Cuadernos de Gobierno y Administración Pública ISSN: e-2341-4839

https://dx.doi.org/10.5209/cgap.65911

\title{
La ruptura del contrato de lealtad. Evolución del empleo científico- técnico en el sector público español
}

\author{
José María de Luxán Meléndez ${ }^{1}$
}

Recibido: 06/03/2019 Aceptado: 18/06/2019

Resumen. El sector público se caracteriza por su dependencia del poder político, su especialización en el interés general, y por la utilización masiva del contrato de lealtad que para garantizar la imparcialidad y profesionalidad de los empleados públicos incorpora una exigencia de mérito y capacidad en su selección y promoción, y una garantía de inamovilidad reforzada. A esta idea se asocia una retribución mayor para los nombramientos y contratados indefinidos, que para los temporales, y para estos un modo de selección más rápido, que se adapte a necesidades inmediatas y no a las exigencias del ingreso en una carrera profesional, que se presume de larga duración, por lo que una variación significativa del peso de la temporalidad en el sector público indica una dualidad de las relaciones laborales y una importante disfunción de la naturaleza del empleo público que altera la calidad del servicio público.

Palabras clave: Políticas Públicas; Institucionalismo; Temporalidad; Feminismo; Empleo público y España.

\section{[en] Public employment's policies in Spain (1996-2017): Diagnosis and a modernization/efficiency agenda}

\begin{abstract}
In order to analyze the public employment policies, the size and production costs of the Spanish administration are described, which is compared with that of the countries of the European Union and the OECD area. Data are presented on the evolution of technical scientific employment, the aging of public employees, the temporality, and the result of some variables of equality policies. In the discussion it is emphasized that the Spanish administration is small and relatively expensive, that the loyalty contract has been questioned and that it may have lost the capacity for innovation and leadership, and that it acts within a rigid and centralized institutional framework to which it is missing comprehensive statistical information. Three lines of change are presented: Increase employment and stabilize spending; Grow in innovation and ensure a sustainable career; promote social dialogue, and outline a proposal to develop a public employment statistics.
\end{abstract}

Keywords: Public policies; Institutionalism; Feminism; Public employment and Spain.

Sumario: 1. Introducción. 2. Los datos: Comparación de fuentes. 3. Evolución del empleo público. 4. Inamovilidad del empleo público. 5. El empleo científico-técnico. 6. Discusión y conclusiones. Bibliografía.

Cómo citar: De Luxán Meléndez, J.M., La ruptura del contrato de lealtad. Evolución del empleo científicotécnico en el sector público español, en Cuadernos de Gobierno y Administración Pública 6-2, 71-91.

1 Centro de Estudios Políticos y Constitucionales / Instituto Complutense de Ciencia de la Administración jmluxan@cepc.es 


\section{Introducción ${ }^{2}$}

El sector público por su dependencia del poder político, por su especialización en el interés general, se caracteriza por el empleo intensivo de técnicos y profesionales, científicos e intelectuales, y por la utilización del contrato de lealtad, que para garantizar la imparcialidad y profesionalidad de los empleados públicos incorpora una exigencia de igualdad, mérito y capacidad en la selección y promoción de sus empleados, así como una garantía de inamovilidad reforzada.

Junto a este modelo, de modo excepcional, se acepta un ámbito de contratación o nombramiento temporal, para el que se abre un modo de selección más rápido, que se adapte a necesidades coyunturales o a los requerimientos de los sistemas de formación y selección científico-técnica. A esta idea se asocia una retribución mayor y en general mejores condiciones laborales para los nombramientos y contratos fijos o indefinidos.

"El contrato de lealtad, típico de las organizaciones públicas, es aquel en el que el trabajador pone a disposición de su patrono unas capacidades profesionales, recibe instrucciones imprecisas que debe completar con su pericia o su conocimiento del contexto, las especificaciones del trabajo o de los objetivos pueden ser cambiadas en cualquier momento y el desempeño sólo puede ser evaluado en términos de lo que cada uno aporta a la organización" (Olías de Lima, 1995:22).

El contrato de lealtad ayuda a explicar la integración de principios aparentemente opuestos como son la normalización externa propia del comportamiento profesional, y la idea de jerarquía que regula el comportamiento de los empleados. La idea de lealtad se encuadra en el ámbito del contrato psicológico ${ }^{3}$ acuñado en el campo de la psicosociología de las organizaciones, como "um acordo implícito, não formal, baseado em promessas, resultantes de crenças individuais, cruciais na moldagem das atitudes e dos comportamentos dos sujeitos nas suas interações com as partes às quais estão (em determinado período) vinculados. Estudos teóricos e empíricos têm evidenciado que a perceção de incumprimento do contrato psicológico, por parte de um indivíduo, tem implicação ao nível das atitudes e comportamentos" (Magno \& Vivente Castro, 2017: 368).

De acuerdo con su Estatuto ${ }^{4}$ el código de conducta de los empleados públicos prevé que "su actuación perseguirá la satisfacción de los intereses generales de los ciudadanos y se fundamentará en consideraciones objetivas orientadas hacia la imparcialidad y el interés común, al margen de cualquier otro factor que exprese posiciones personales, familiares, corporativas, clientelares o cualesquiera otras que puedan colisionar con este principio". En su elogio de la burocracia, Du Gay subraya que en el servicio público "las formas de conducta que más se valoraban eran la

2 Una primera versión de este trabajo ha sido mejorada con las sugerencias de José Vicente Gómez Rivas, Luis de Luxán Meléndez, José Luis de Ossorno Almecija, y Demetrio Vicente Mosquete, a los que agradezco sus comentarios, aunque sólo soy yo responsable del resultado. Este trabajo se inscribe en una línea de investigación sobre la política de empleo en el sector público que desde 2016 vengo desarrollando en el Centro de Estudios Políticos y Constitucionales y en la Universidad Complutense de Madrid, y se presentó el 22 de noviembre de 2018 en el II Congreso Internacional del Instituto Complutense de Ciencia de la Administración sobre las múltiples caras de la gobernanza ante los retos de la sociedad actual.

3 Sobre el contrato psicológico en la Administración puede verse la Tesis Doctoral de Isabel Paraíso, Política de austeridad y contrato psicológico en la administración pública (Faria Lopes, 2012).

$4 \quad$ Art. 53. 2 de la Ley 7/2007, de 12 de abril, del Estatuto Básico del Empleado Público. 
honestidad, la imparcialidad, la flexibilidad, la habilidad para clarificar opciones destinadas a políticas que compiten entre sí, la capacidad para trabajar en equipo, la integridad y el desinterés" (Du Gay, 2012: 241).

La política de empleo público actúa en un contexto de regulación institucional altamente centralizado que no tiene suficientemente en cuenta la presencia de políticas públicas y centros de poder político diferenciados, y en la que el ámbito de la negociación colectiva aparece limitado y fragmentado (Luxán Meléndez, 2019), que además en los últimos años, opera principalmente desde el marco teórico de la nueva gestión pública, que atrae una lógica de racionalidad mercantil, enfrentada a la racionalidad política del Estado.

La crisis del ideal burocrático (Vallés \& Martí i Puig, 2015: 194-201) se vincula con la expansión y diversificación del estado, en el que, desde el siglo XVIII, el ascenso del gasto público, en términos de PIB, es una historia de éxito político, en el que "la creciente importancia del gasto social ha estado relacionada con otras tres grandes transformaciones sociales: la transición a una democracia más completa, la transición demográfica hacia una tasa de natalidad menor y una vida más prolongada, y el inicio del crecimiento económico sostenido" (Lindert, 2011:36).Sobre el sector público (Stiglitz \& Rosengard, La economía del sector público, 2015) es útil recordar que las diferencias más relevante del Estado con respecto al ámbito privado son inherentes y se derivan de sus características esenciales: "la asociación universal e ineludible, y sus otros poderes (fiscales y redistributivos), sus responsabilidades fiduciarias (con sus consecuencias para la política de empleo y gasto) y de sus limitaciones intrínsecas relacionadas, por ejemplo, con los derechos de propiedad y la celebración de contratos" (Stiglitz, 1993: 93).

Sin embargo la nueva gestión pública se ha nutrido de una crítica a la burocracia que planteó su reforma desde un paradigma de gobierno empresarial (Osborne \& Gaebler, 1995), sobre el que se ha señalado que alguno de sus principios esenciales (gerencialismo, orientación a resultados, agencialismo) disuelven la vinculación de la sociedad con la administración pública, puesto que con la distancia que proponen entre la política y la agencias públicas, se desvanece la racionalidad estatal para trasladar la responsabilidad a los gestores y conducir el ámbito de sus decisiones exclusivamente a una racionalidad técnica (Du Gay, 2012).

Los países mediterráneos y latinos conforman un grupo en el que el coste y el tamaño de la administración, apuntan pautas diferenciadas del resto de Europa, tienen un coste medio alto y un tamaño medio bajo. Cuentan con una administración de tamaño próxima a la media Europea, en un intervalo muy amplio, entre un 8 y $22 \%$ de empleados sobre la población activa, más grande en Francia y más pequeña en España, mientras el coste de las retribuciones, oscila en un intervalo que va de un 10 a un $13 \%$ del Producto Interior Bruto, algo más alto que el promedio europeo, también mayor en Francia y menor en España. (Luxán Meléndez, 2016).

Un modelo de empleo en el que la brecha salarial de género en el ámbito público, según el indicador que se utilice oscila entre un 4.2 y un 13\%, está muy lejos de la del sector privado, que se mueve sobre un 19\%, y cuya la falta de paridad es un indicador de discriminación laboral indirecta asociada a la carrera profesional. La trayectoria profesional depende de las normas de provisión de puestos, que se realizan mediante convocatorias específicas, individualizadas para cada puesto, lo que facilita la continuidad de pautas discriminatorias. En las organizaciones en las que las 
decisiones se adoptan desde el principio de jerarquía, el notable incremento de la proporción de directivas, que llega a un 39\% se vincula al aumento de la proporción de empleo femenino en los cuerpos superiores, y en las organizaciones de lógica profesional, en las que prima el saber experto, el peso de las mujeres en las posiciones más relevantes, es más reducido, un $24 \%$ en los órganos centrales de la judicatura y un $21 \%$ de catedráticas, y no depende del incremento del peso femenino en la categorías previas. (Luxán Meléndez, 2018).

En un contexto señalado por la crisis financiera y económica internacional de 2008, que en España se extiende hasta 2013, al ralentizar la presencia de nuevos técnicos, profesionales, científicos e intelectuales, al reducir la presencia de las cohortes de edad formadas en la democracia, al mantener abierta una importante brecha salarial entre hombres y mujeres, o al incrementar el uso de la temporalidad, los poderes públicos pueden haber frenado su capacidad de comprensión y liderazgo de la sociedad del conocimiento, y al modificar las pautas de las relaciones laborales del sector público alterar las condiciones del contrato de lealtad que sustenta la administración pública. Sin embargo la inspección de trabajo española sólo actúa parcialmente en el ámbito del empleo público.

En este trabajo en primer lugar se analizan las características de las fuentes estadísticas del empleo público, se repasa la evolución del empleo público, en especial del grupo de profesionales y técnicos, científico e intelectuales de las administraciones públicas, se compara con la situación Europea y de los países de las OCDE, y sobre la temporalidad o la igual de género se describe la evolución, entre 1996 y 2019, de alguno de sus rasgos.

\section{Los datos: Comparación de fuentes ${ }^{5}$}

E1 sector público ${ }^{6}$ incluye la Administración General del Estado, las Administraciones de las Comunidades Autónomas, las entidades que integran la Administración Local, y el sector público institucional, que incorporan a los empleados de todas las instituciones públicas, que de acuerdo con el Estatuto Básico del Empelado público ${ }^{7}$

\footnotetext{
Este epígrafe es una versión ampliada y actualizada con datos hasta 2018 de la comparación de fuentes del artículo "El impacto de la crisis en las retribuciones del sector público" (Luxán Meléndez, 2016).

6 Art. 2 de la Ley 40/2015, de 1 de octubre, de Régimen Jurídico del Sector Público. BOE núm. 236, de 02/10/2015

7 El EBEP se refiere a las administraciones (Art. 2 Real Decreto legislativo 5/2015, de 30 de octubre, por el que se aprueba el texto refundido de la Ley del Estatuto Básico del Empleado Público, BOE nº 261, de 31/10/2015), pero parce excluir a los empleados de las instituciones públicas que no tengan esta consideración (entidades de derecho privado vinculadas o dependientes de las Administraciones Públicas. Artículo 2.3 de la Ley de Régimen Jurídico...). El EBEP incluye la Administración General del Estado, las Administraciones de las comunidades autónomas y de las ciudades de Ceuta y Melilla, las Administraciones de las entidades locales, los organismos públicos, agencias y demás entidades de derecho público con personalidad jurídica propia, vinculadas o dependientes de cualquiera de las Administraciones Públicas, y las Universidades Públicas. (Art. 2 del EBEP). Sin perjuicio de su Este epígrafe es una versión ampliada y actualizada con datos hasta 2018 de la comparación de fuentes del artículo "El impacto de la crisis en las retribuciones del sector público" (Luxán Meléndez, 2016).

Art. 2 de la Ley 40/2015, de 1 de octubre, de Régimen Jurídico del Sector Público. BOE núm. 236, de $02 / 10 / 2015$.

El EBEP se refiere a las administraciones (Art. 2 Real Decreto Legislativo 5/2015, de 30 de octubre, por el que se aprueba el texto refundido de la Ley del Estatuto Básico del Empleado Público, BOE n 261, de 31/10/2015), pero parce excluir a los empleados de las instituciones públicas que no tengan esta consideración (entidades de derecho
} 
(EBEP) pueden ser funcionarios de carrera, funcionarios interinos, personal laboral, ya sea fijo, por tiempo indefinido o temporal, y personal eventual ${ }^{8}$.

El sector público no dispone de un sistema de información estadística integral que vincule el registro de función pública con las estadísticas laborales o con los registros fiscales, y de la seguridad social. Contamos con cinco fuentes principales" la Encuesta de Población Activa (EPA); el Boletín Estadístico del Personal al Servicio de las Administraciones Públicas (BEPSAP); la estadística de Mercado de trabajo y pensiones en las fuentes tributarias; la estadística de la Seguridad Social y la síntesis de Contabilidad Nacional.

Tabla 1. Características de las fuentes estadísticas sobre el empleo público

\begin{tabular}{|l|l|l|}
\hline \multirow{5}{*}{ Por la referencia conceptual } & $\begin{array}{l}\text { Asalariados del sector } \\
\text { público }\end{array}$ & $\begin{array}{l}\text { - Encuesta de Población Activa } \\
- \text { Contabilidad Nacional } \\
- \text { Mercado de trabajo y pensiones } \\
\text { en las fuentes tributarias }\end{array}$ \\
\cline { 2 - 3 } & $\begin{array}{l}\text { Asalariados del sector } \\
\text { público en el régimen } \\
\text { general de la Seguridad } \\
\text { Social }\end{array}$ & $\begin{array}{l}\text { - Estadística de la Seguridad } \\
\text { Social }\end{array}$ \\
\cline { 2 - 3 } & $\begin{array}{l}\text { Empleados públicos de } \\
\text { duración indefinida o } \\
\text { temporal de más de seis } \\
\text { meses }\end{array}$ & $\begin{array}{l}\text { - Boletín Estadístico del } \\
\text { Personal al Servicio de las } \\
\text { Administraciones Públicas }\end{array}$ \\
\hline
\end{tabular}

privado vinculadas o dependientes de las Administraciones Públicas. Artículo 2.3 de la Ley de Régimen Jurídico...). El EBEP incluye la Administración General del Estado, las Administraciones de las comunidades autónomas y de las ciudades de Ceuta y Melilla, las Administraciones de las entidades locales, los organismos públicos, agencias y demás entidades de derecho público con personalidad jurídica propia, vinculadas o dependientes de cualquiera de las Administraciones Públicas, y las Universidades Públicas. (Art. 2 del EBEP). Sin perjuicio de su legislación propia, el régimen estatutario público se extiende al personal funcionario de las Cortes Generales y de las asambleas legislativas de las comunidades autónomas, al Personal funcionario de los demás Órganos Constitucionales del Estado y de los órganos estatutarios de las comunidades autónomas; a Jueces, Magistrados, Fiscales y demás personal funcionario al servicio de la Administración de Justicia, al Personal militar de las Fuerzas Armadas, al personal de las Fuerzas y Cuerpos de Seguridad; al personal retribuido por arancel; al personal del Centro Nacional de Inteligencia; al personal del Banco de España y del Fondo de Garantía de Depósitos de Entidades de Crédito, al personal funcionario de la Sociedad Estatal Correos y Telégrafos (Art. 4 y 5 del EBEP).

8 Artículo 8. Real Decreto legislativo 5/2015, de 30 de octubre, por el que se aprueba el texto refundido de la Ley del Estatuto Básico del Empleado Público (EBEP), BOE nº 261, de 31/10/2015.La Ley de Régimen Jurídico del sector público y el EBEP excluyen de su ámbito a los que no desempeñan funciones retribuidas en las Administraciones Públicas, y además tengan o no retribuciones también a los titulares de los órganos constitucionales a los que ambas leyes no se refieren directamente, lo que descartaría al Rey; a los miembros de las Cortes Generales, de las Asambleas legislativas de las Comunidades Autónomas, y de las Corporaciones locales; a los miembros del Gobierno, y de los Consejos de Gobierno; a los titulares de los órganos dependientes de las Cortes Generales o de las asambleas legislativas y a los magistrados del Tribunal Constitucional.

9 Además publican cifras de empleo público la Mutualidad General de Funcionarios Civiles del Estado (MUFACE), el Instituto Social de las Fuerzas Armadas (ISFAS) y la Mutualidad General Judicial (MUGEJU). Para comparaciones internacionales son imprescindibles las estadísticas e informes de EUROSTAT, de la OCDE, y la base de datos de la OIT. 


\begin{tabular}{|c|c|c|}
\hline \multirow{6}{*}{$\begin{array}{l}\text { Por el origen de la } \\
\text { información }\end{array}$} & \multirow{3}{*}{ Registro administrativo } & $\begin{array}{l}\text { - Boletín Estadístico del } \\
\text { Personal al Servicio de las } \\
\text { Administraciones Públicas }\end{array}$ \\
\hline & & $\begin{array}{l}\text { - Mercado de trabajo y pensiones } \\
\text { en las fuentes tributarias }\end{array}$ \\
\hline & & - Estadística de la Seguridad Social \\
\hline & Información administrativa & $\begin{array}{l}\text { - Boletín Estadístico del } \\
\text { Personal al Servicio de las } \\
\text { Administraciones Públicas }\end{array}$ \\
\hline & Información muestral & - Encuesta de Población Activa \\
\hline & Elaboración de síntesis & - Contabilidad Nacional \\
\hline \multirow{3}{*}{ Por el ámbito geográfico } & En todo el mundo & $\begin{array}{l}\text { - Boletín Estadístico del } \\
\text { Personal al Servicio de las } \\
\text { Administraciones Públicas }\end{array}$ \\
\hline & Residentes en España & $\begin{array}{l}\text { - Estadística de la Seguridad } \\
\text { Social } \\
\text { - Encuesta de Población Activa } \\
\text { - Contabilidad Nacional }\end{array}$ \\
\hline & En parte de España & $\begin{array}{l}\text { - Mercado de trabajo y pensiones } \\
\text { en las fuentes tributarias }\end{array}$ \\
\hline \multirow{4}{*}{ Por la referencia temporal } & Anuales & $\begin{array}{l}\text { - Contabilidad Nacional } \\
\text { - Mercado de trabajo y pensiones } \\
\text { en las fuentes tributarias (todo } \\
\text { el año) }\end{array}$ \\
\hline & Semestral & $\begin{array}{l}\text { - Boletín Estadístico del } \\
\text { Personal al Servicio de las } \\
\text { Administraciones Públicas (en } \\
\text { el día de referencia) }\end{array}$ \\
\hline & Trimestrales & $\begin{array}{l}\text { - Encuesta de Población Activa } \\
\text { (en la semana de referencia) }\end{array}$ \\
\hline & Mensuales & $\begin{array}{l}\text { - Estadística de la Seguridad } \\
\text { Social (en el mes de referencia) }\end{array}$ \\
\hline \multirow{3}{*}{ Por su empleo internacional } & EUROSTAT & - Encuesta de Población Activa \\
\hline & OCDE & - Encuesta de Población Activa \\
\hline & OIT & - Encuesta de Población Activa \\
\hline
\end{tabular}

Fuente: Elaboración propia.

Entre ellas, en este trabajo, se prefieren los datos de la Encuesta de Población Activa (EPA) que incluye casi la totalidad del empleo público, cuenta con la serie 
más amplia, aporta información desagregada, y permite una comparación nacional e internacional homogénea.

La EPA y los datos que proporciona función pública en el BEPSAP son las estadísticas con información más desagregada. Son estadísticas coherentes, que tienen una alta correlación ${ }^{10}$, y sus diferencias metodológicas ${ }^{11}$, si bien evolucionan de forma paralela (Figura 1), justifican que las cifras que proporciona la EPA difieran mucho de las que recoge el BEPSAP.

Entre 2000 y 2018, en todos los años, los datos de la EPA son sensiblemente superiores a los de función pública. En promedio anual la diferencia es de 436.000 empleados, lo que supone un 17,4\% adicional en la EPA sobre la estadística del BEPSAP.

$\mathrm{La} \mathrm{EPA}^{12}$ recoge información de una muestra continua, representativa de la población residente en España, en la que, al igual que para el resto de la economía, son los encuestados los que señalan su vinculación laboral referida a la semana en que se realiza cada entrevista.

Por su parte la estadística que publica el BEPSAP ${ }^{13}$, que excluye a los empleados con contratos temporales de duración inferior a 6 meses, es una explotación de fuentes administrativas, cuya referencia principal es el Registro Central de Personal, que en el primer semestre toma como referencia a los que están empleados el 1 de enero y en el segundo a los que están empleados el 1 de julio.

$10 \mathrm{R}^{2}$ 0,85 para el periodo 2000 a 2018 entre BESAP a 1 de enero y EPA anual.

11 Para las características de las distintas fuentes estadísticas sobre el empleo público son relevantes los trabajos de Antonio Montesinos, Javier Pérez, Roberto Ramos (Montesinos, Pérez \& Ramos, 2014: 29-32), de Manuel Arenilla y David Delgado (Arenilla Sáez \& Delgado Ramos, 2014: 299-303) y de Marta Martínez (Martínez y Pérez, 2017: 11-12).

12 La Encuesta de Población Activa, recoge información sobre los asalariados del sector público que viven en España, lo que excluye datos sobre los empleados de la administración exterior. La EPA que se realiza desde 1964, es una investigación de periodicidad trimestral, dirigida a la población que reside en viviendas familiares del territorio nacional, e incluye a las "personas con trabajo por cuenta ajena o asalariadas que durante la semana de referencia hayan trabajado, incluso de forma esporádica u ocasional, al menos una hora a cambio de un sueldo, salario u otra forma de retribución conexa, en metálico o en especie". (Instituto Nacional de Estadística, 2017, pág. 5) La muestra inicial es de unas 65.000 familias al trimestre que equivalen aproximadamente a 180.000 personas (Instituto Nacional de Estadística. Area de Diseño de Muestras y Evaluación de Resultados, 2016). Desde 1976 publica información sobre los asalariados del sector público, pero hay una ruptura en la serie en 1995 y en 2001.

13 La estadística de función pública es principalmente una explotación de los datos del Registro Central de Personal, y entre otros, excluye a una parte importante de los empleados de de las Comunidades Autónomas y de la Administración local: contratados temporales de menos de 6 meses y un sector de empleados de la administración institucional. Desde 1990 el BEPSAP “incluye el conjunto de los efectivos que prestan servicio en la Administración Pública Estatal (Administración General del Estado, Fuerzas y Cuerpos de Seguridad del Estado, Fuerzas Armadas, Administración de Justicia y Entidades Públicas Empresariales y Organismos Públicos con régimen específico); las Administraciones de las Comunidades Autónomas; la Administración Local (Ayuntamientos, Diputaciones, Cabildos y Consejos Insulares) y las Universidades. Y no incluye a los altos cargos de las Administraciones Públicas, a los Cargos electos, al personal al servicio de los Órganos Constitucionales y Órganos equivalentes en las Comunidades Autónoma, al personal de Entidades Públicas Empresariales y Organismos Públicos con régimen específico de las Comunidades Autónomas y de la Administración Local equivalentes a los organismos públicos de la Administración General del Estado, al personal de empresas públicas, fundaciones, mutuas, consorcios y sector público no administrativo de las Administraciones Públicas, al. Personal en formación y prácticas, reserva, segunda actividad, o cualquier otra situación que no sea la de servicio activo de las Comunidades Autónomas y las Entidades Locales, y al Personal laboral con contratos de duración inferior a 6 meses de las Comunidades Autónomas, y al Personal del Centro Nacional de Inteligencia". (Registro Central de Personal, 2017: 4-5). 
Figura 1. Número de empleados públicos en España.

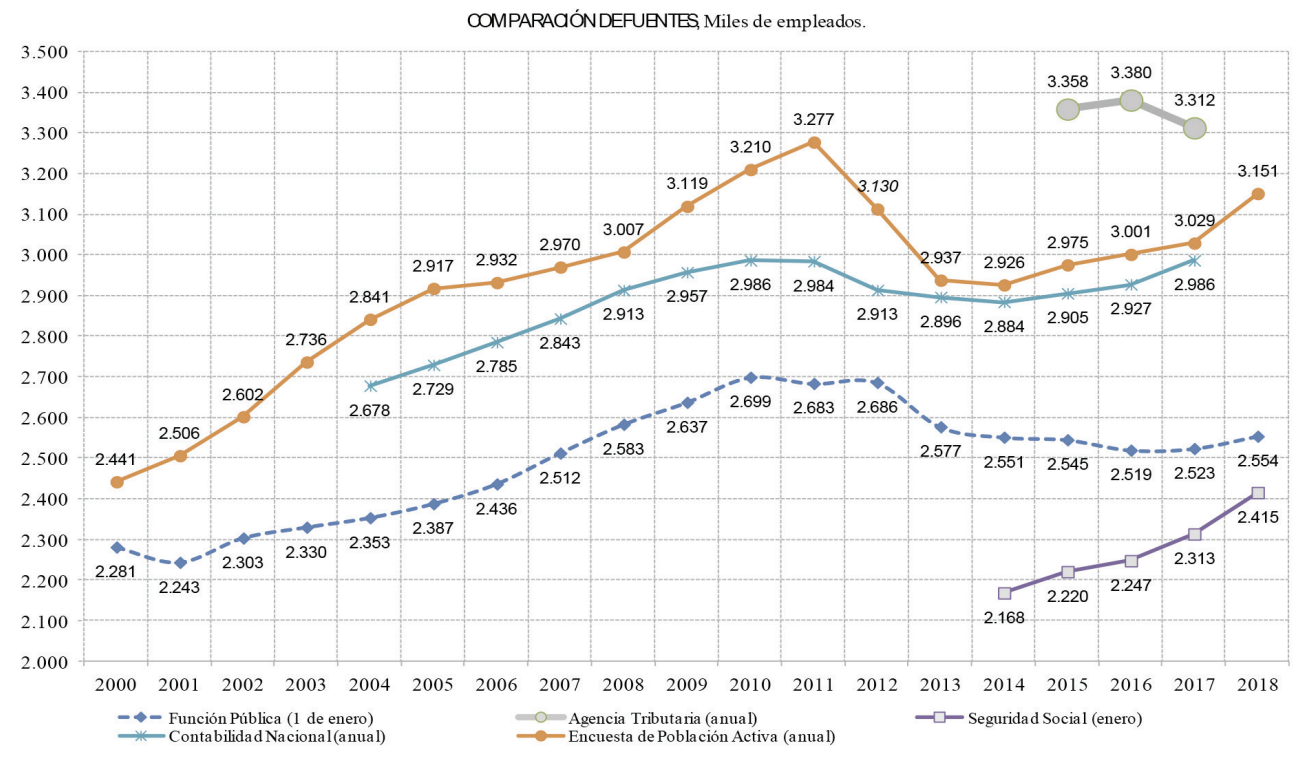

La estadística que elabora la Agencia Tributaria ${ }^{14}$ es una explotación de fuentes administrativas, que desde 2015 contiene datos sobre el número de personas ${ }^{15}$ que a lo largo del año en algún momento han estado empleados en las administraciones públicas, lo que incluye a los que están empleados durante todo el año, y a los nuevos tengan un contrato o nombramiento indefinido o temporal, e igualmente a los que también a lo largo del año han dejado de estar empleados sea por despido, renuncia, fin de contrato, excedencia, sanción, inhabilitación, jubilación, o fallecimiento.

Contabilidad Nacional realiza una estadística de síntesis que desde 2004 incorpora datos agregados del número de personas empleadas en el sector administraciones públicas, que toma como referencia la EPA, las remuneraciones de los empleados públicos según la Cuenta Nacional de la Intervención General de Administración del Estado (IGAE), y la estadística del BEPSAP, y significativamente difiere tanto de la EPA como de función pública (BEPSAP).

La EPA y Contabilidad Nacional no guardan una correlación positiva alta $^{16}$, y sus diferencias metodológicas, justifican que aunque evolucionen paralelamente (Figura 1), las cifras que proporciona Contabilidad Nacional en algunos años difieran mucho de las que recoge la EPA. Aunque las diferencias cuantitativas sean mayores, Conta-

14 La estadística descansa en la relación de perceptores de rentas que presentan los empleadores y entidades pagadoras de pensiones o de prestaciones por desempleo mediante la Declaración Resumen Anual de Retenciones e Ingresos a Cuenta sobre Rendimientos del Trabajo, de determinadas actividades económicas, premios y determinadas imputaciones de renta (Metodología. Mercado de Trabajo y Pensiones en Las Fuentes Tributarias).

15 Son personas asalariadas las que reciben una contraprestación dineraria en concepto de rendimiento de trabajo, contadas de forma única independientemente de que hayan trabajado para una o varias empresas o entidades (Metodología. Mercado de Trabajo y Pensiones en Las Fuentes Tributarias).

$16 \mathrm{R}^{2}$ 0,60 entre Contabilidad nacional y EPA anual para el periodo 2004 a 2017. 
bilidad Nacional guarda una mayor correlación ${ }^{17}$ con los datos publicados por función pública (BEPSAP).

Entre 2004 y 2017, en todos los años, los datos de la EPA son superiores a los de Contabilidad Nacional. En promedio anual la diferencia es de 133.000 empleados, lo que supone un 4,4\% adicional en la EPA sobre la estadística de Contabilidad Nacional, distancia que sin embargo desde 2013, en media anual, se ha reducido a un 1,8\%.

En el mismo periodo los datos de Contabilidad Nacional, en todos los años, son superiores a los de función pública (BEPSAP). En promedio anual la diferencia es de 335.000 empleados, lo que supone un 11,6\% adicional en Contabilidad Nacional sobre la estadística función pública (BEPSAP), distancia que desde 2013, en media anual, ha aumentado hasta un $12,9 \%$.

La estadística de la Seguridad Social desde octubre de 2013 publica información exclusivamente desagregada por género y provincia sobre los empleados públicos, funcionarios o laborales, incluidos en el régimen general de la seguridad social cuyo número se ha incrementado progresivamente como consecuencia de los cambios ${ }^{18}$ en el régimen de seguridad social del empleo público.

En ningún caso la etiqueta empleo público recoge a los trabajadores, contratados por empresas privadas, que mediante distintitas formulas realizan toda su actividad exclusivamente y de manera permanente para el Estado, y la desarrollan siempre completamente en instalaciones de las administraciones públicas.

Conviene insistir en que las diferencias entre las distintas estadísticas no prejuzgan la calidad de las fuentes ${ }^{19} \mathrm{y}$ que la utilidad ${ }^{20}$ de cada una depende de los objetivos de cada investigación o del aspecto que se quiera analizar. Para realizar comparaciones internacionales o sectoriales sólo se puede emplear la EPA, mientras que para estudiar las características departamentales sólo es útil el Registro. Para describir el tamaño y la evolución del empleo público en el ámbito de la Ciencia Política es usual utilizar como referencia fuentes estadísticas basadas en operaciones administrativas, pero también, sobre todo, en el campo de las políticas públicas ${ }^{21}$ es habitual emplear las estadísticas de Contabilidad Nacional y del mercado de trabajo.

$17 \quad \mathrm{R}^{2}$ 0,74 entre Contabilidad nacional anual y función pública (BEPSAP) para el periodo 2004 a 2017.

18 El Real Decreto-ley 13/2010, de 3 de diciembre, de actuaciones en el ámbito fiscal, laboral y liberalizadoras para fomentar la inversión y la creación de empleo, ha establecido como obligatorio el encuadramiento en el Régimen General de la Seguridad Social de todos los funcionarios de nuevo ingreso.

19 Por el contrario Arenilla y Delgado consideran que "El análisis de cada una de las fuentes que suministran los datos de empleo público permite inferir, pese a las dificultades comparativas, que aunque no se trata de la fuente más completa, sí resulta la más fiable, desde una perspectiva metodológica y sistemática, el Boletín Estadístico del Personal al Servicio de las Administraciones Públicas, del Registro Central de Personal. El Boletín Estadístico, pese a no recoger - como sí hace la Encuesta de Población Activa- a todos los asalariados públicos, incluye a la mayoría de los colectivos según una metodología eminentemente objetiva -el recuento-, con datos recabados tanto del propio Registro Central de Personal (Administración pública estatal) como de las comunidades autónomas, las entidades locales y las universidades" (Arenilla Sáez \& Delgado Ramos, 2014: 302).

20 Para ver la dificultad de ambas operaciones estadísticas se pueden señalar dos ejemplos: En la EPA un 0,35\% de los asalariados públicos cuando se les pregunta por la administración en la que trabajan no la identifican y la EPA presenta los datos como otro tipo o no sabe, mientras que en el BEPSAP al recoger el número de profesores asociados de la universidad no se tiene en cuenta que una parte de ellos tienen su actividad principal en la administración por lo que, a pesar de las notas metodológicas, se induce a contarlos dos veces cuando se suman las distintas administraciones.

${ }^{21}$ Por señalar un solo caso, es muy relevante que Jacint Jordana y Carles Ramió en Estadísticas Históricas de España referencien la evolución del empleo público con la Encuesta de Población Activa (Jordana \& Ramió, 2005 (2a): 1003). 
Sobre el número de empleados públicos Arenilla opta por la estadística del Registro Central de Personal (Arenilla Sáez \& Delgado Ramos, 2014) y por citar sólo otro ejemplo, en el que los datos del Registro son imprescindibles para estudiar la organización interna de un departamento ministerial, Salvador Parrado para señalar el número y la evolución de los empleados públicos entre 1983 y 2015 también se refiere a datos del Boletín estadístico del personal al servicio de las Administraciones Públicas (Parrado, 2017: 317-321) y para presentar la evolución de la función pública estatal según niveles utiliza datos de la Intervención General del Estado (Parrado, 2017: 322).

\section{Evolución del empleo público ${ }^{22}$}

De acuerdo con la Encuesta de Población Activa, entre 1976 y 2019, el número total de empleados públicos (Figura 2) ha pasado de 1.358 .100 a 3.213.600. En términos generales desde 1976 hay gran continuidad en la orientación expansiva de la política del empleo público, coherente con los incrementos de la población y del PIB.

Un incremento medio de $0,51 \%$ intertrimestrales, que quebró entre el cuarto trimestre de 2011 y el cuarto de 2013, un periodo en el que se acumuló una disminución de 397.200 empleos netos, con un ritmo medio de $-1,31 \%$ intertrimestrales, y aunque un ajuste en el empleo público no sea la primera vez que se produce, este es el que comprende un periodo de disminución continuada de mayor duración e intensidad: 9 trimestres seguidos y una disminución del 12\%.

Figura 2. El empleo público en España (1976-2019)

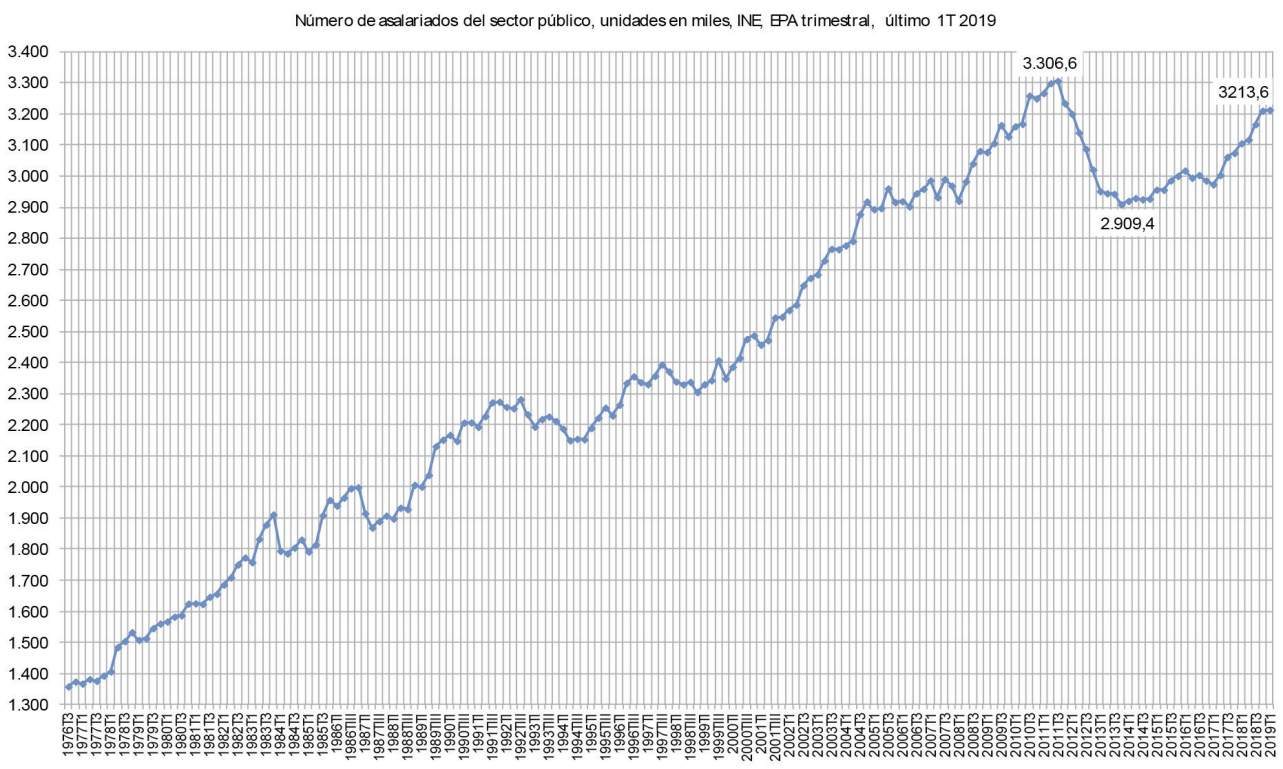

22 La primera parte de este epígrafe es una versión revisada y actualizada con datos que incluyen el primer trimestre de 2019 de parte del epígrafe 3.1 de mi artículo "Las políticas de empleo público en España (1996-2017): diagnóstico y propuestas para su modernización y eficiencia” (Luxán Meléndez, 2019). 
Por el contario a partir de 2004 en un escenario de escasa variación o de disminución de la población y del PIB, la política de empleo público, medida por la variación del número de empleados, es muy dispar:

a. Durante el periodo de gobierno del presidente Zapatero la evolución del empleo público tuvo dos pautas muy diferentes: una de estabilización y luego otra de expansión. En la primera legislatura, hasta el segundo trimestre de 2008, el número total de empleados se estabilizó sobre 2.900 .000 , cifra hasta ese momento era la más alta desde 1976. Mientras que en la segunda legislatura, pero sobre todo desde el tercer trimestre de 2008, en un contexto marcado por la crisis económica, el empleo público recobró la senda del crecimiento hasta el tercer trimestre de 2011, y alcanzó una cifra todavía más alta, con más de 3.300.000. Esta política de nuevo expansiva se paralizó al final de la legislatura, en el cuarto trimestre de 2011, inmediatamente después del movimiento del 15-M de 2011, y meses antes de las elecciones de diciembre de 2011, que tuvieron como resultado la derrota del PSOE y la mayoría absoluta del PP.

b. Durante el gobierno del presidente Rajoy, la evolución del empleo público ha tenido también dos pautas diferenciadas: primero de disminución del empleo público, y luego de recuperación. Desde el primer trimestre de 2012, hasta el cuarto trimestre de 2013, dos años completos de reducción del empleo público, hasta situarse de nuevo sobre 2.900.000, como en la primera legislatura del presidente Zapatero. Y a partir de 2014 volverá a crecer el empleo público hasta situarse en 3.117.800 en el segundo trimestre de 2018.

c. Desde el tercer trimestre de 2018, en el gobierno del presidente Sánchez, el empleo público sigue creciendo hasta alcanzar 3.213.600 en el primer trimestre de 2019.

\section{Inamovilidad del empleo público}

Dado que el Estatuto Básico del Empleado Público refuerza las garantías de inamovilidad, es de esperar que sean más numerosos los contratados indefinidos en el ámbito público que los del sector privado y que su variación esté menos asociada al ciclo económico y que no esté sustancialmente vinculado al ciclo político.

Para medir el alcance de la inamovilidad del empleo público, una de las características con las que se identifica a los sistemas de mérito y que le diferencian tanto de los modelos de spoils system, como de algunas pautas laborales del empleo en el sector privado, se puede utilizar como criterio la proporción del número de empleados que cuentan con un contrato o nombramiento fijo o de duración indefinida.

Desde esta perspectiva, entre 2002 y 2018, en la evolución (Figura 3) del sector público se pueden señalar cuatro etapas:

a. Inicialmente, hasta 2005, en el sector público la estabilidad del empleo es mucho mayor que en el sector privado. Y la diferencia entre ambos permanece estable, de media, la proporción de trabajo indefinido fue doce puntos más alta en el sector público (77\%) que en el privado $(65 \%)$. 
b. Entre otros factores, como consecuencia del cambio de orientación de la política laboral ${ }^{23}$, en el trienio 2006-2008, en el sector privado se incrementó muy rápidamente el porcentaje de contratos fijos, hasta igualarse a los del sector público que, a diferencia del privado, se mantendrá estable, con un promedio del $74 \%$.

c. Durante los años centrales de la crisis, entre 2009 y 2011, en un contexto de masivo incremento del paro, en ambos sectores la tasa de trabajo indefinido, permanece de media trimestral, en un $75 \%$.

d. A partir de 2012, en el ámbito público, en un contexto de reducción del empleo público, se observa un incremento del peso relativo de los contratos o nombramientos permanentes, que, con un $81 \%$, alcanzará su cota más alta en el primer trimestre de 2013.

e. Desde 2013, el peso de los contratos indefinidos disminuirá progresivamente en los sectores público y privado. La disminución es especialmente intensa en el sector público que llega hasta $73,2 \%$, por debajo de la proporción de indefinidos del ámbito privado que llega hasta un $74,4 \%$. En otros términos en el sector público de manera constante desde el primer trimestre de 2013 se ha incrementado la temporalidad, que ha pasado de un $19 \%$ a un $27 \%$ en el primer trimestre de 2019, con un incremento neto en cinco años de 303,100 empleos temporales adicionales que absorbe la totalidad del descenso de los empleos de duración indefinida, que en el mismo periodo se redujeron en 41.200 empleos netos, lo que se tradujo en un saldo de 261,900 empleos adicionales en el ámbito público.

Figura 3. Asalariados con nombramiento o contrato indefinido

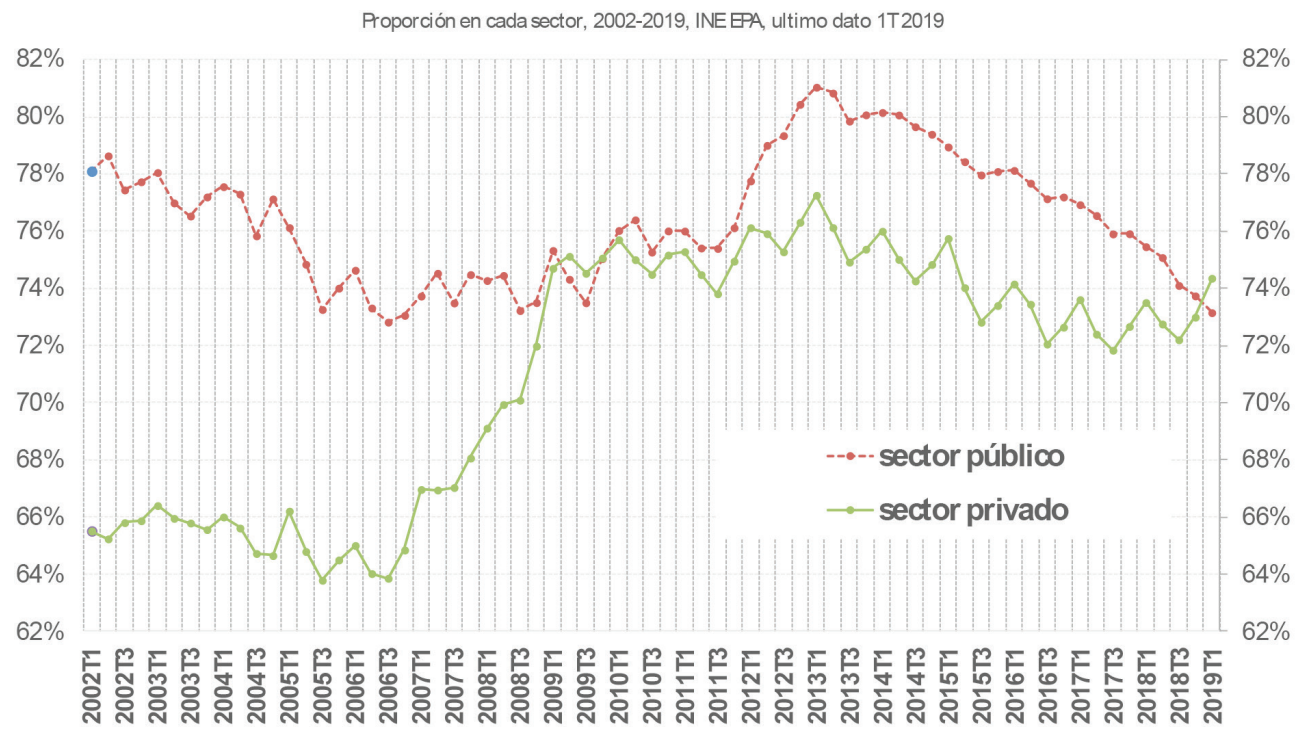

23 Acuerdo para la mejora del crecimiento y del empleo de 9 de mayo de 2006 firmado entre el Gobierno y los Sindicatos. 
Tras el cambio de la política laboral que afecta al sector privado, desde 2009 hasta 2018, pese a considerarse excepcional, la utilización de la contratación temporal en el sector público es equivalente a la del sector privado, de media respectivamente un $23 \%$ y un $26 \%$ del total de los empleados de cada sector.

Frente a la idea de que el empleo público es esencialmente indefinido, o al menos que es más inamovible que el empleo del sector privado, llama la atención el alto grado de elasticidad del empleo público temporal, que desde 2009, tiene primero un brusco descenso y luego un rápido crecimiento.

Pero sobre todo, otra perspectiva contradice igualmente la presunción de inamovilidad del sector público (figura 4). Si la duración del contrato se segmenta por edades, por segundo trimestre consecutivo en el $1^{\circ}$ trimestre de 2019 más de la mitad de los empleados públicos de menos de 40 años tienen un contrato temporal, mientras que entre los empleados del sector privado la proporción de los que tienen un contrato temporal se reduce, en más de 16 puntos, hasta un $36,2 \%$, ahora en una proporción mayor que en 2009 (31,9\%). A diferencia del sector privado, en el sector público la evolución del trabajo temporal no tiene un carácter temporal.

Figura 4. Proporción de empleados de menos de 40 años con contrato temporal sobre el total de empleados de cada sector de menos de 40 años

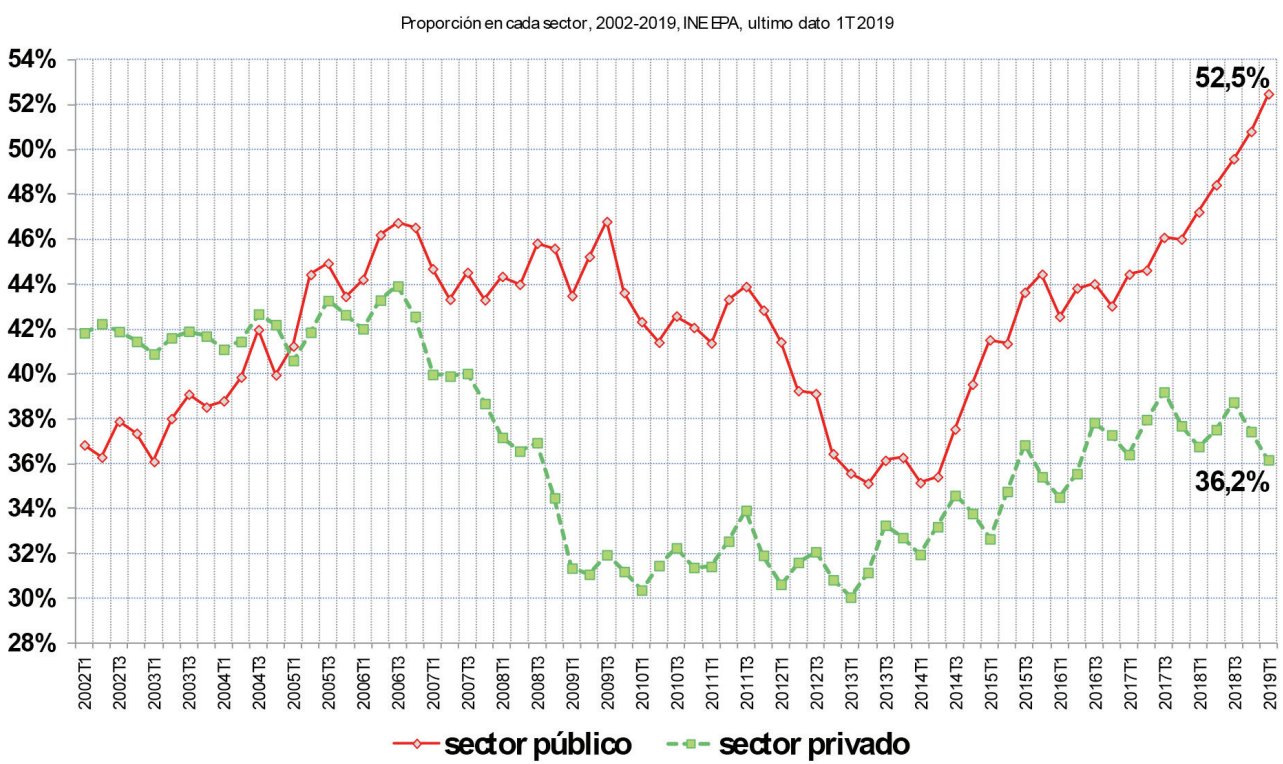

Y por el contrario entre los empleados públicos de más de 40 años la temporalidad, también en aumento llega a una sexta parte (17,8\%), y sólo es algo mayor que en al ámbito privado que llega a un $17,4 \%$.

Esta dualidad joven-temporal versus mayor-indefinido, en el ámbito del sector público es mayor entre las mujeres (figura 5) que entre los hombres, mientras que casi no hay diferencias de género en el sector privado. 
Figura 5. Proporción de empleadas de menos de 40 años con contrato o nombramiento temporal sobre el total de empleadas de menos de 40 años

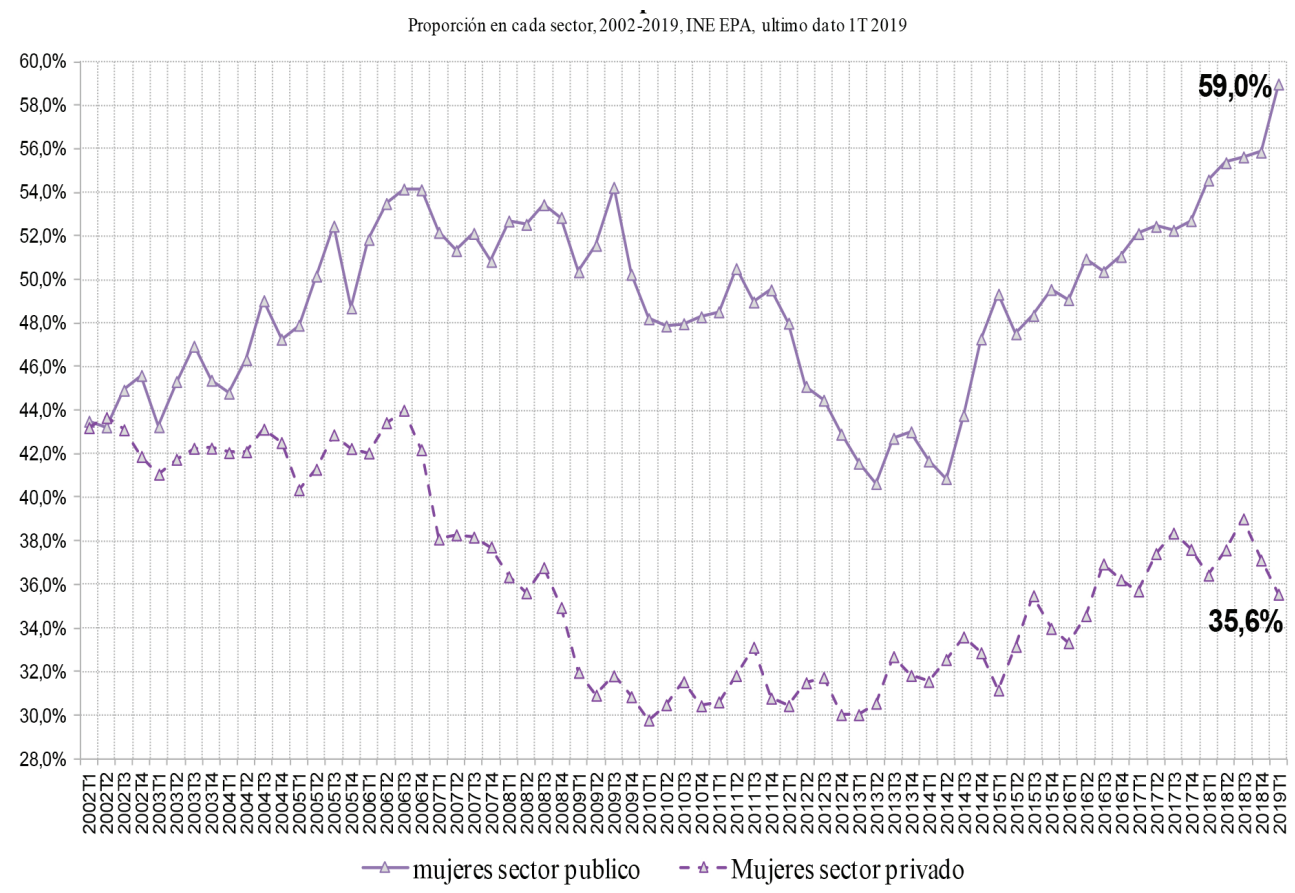

Así entre las mujeres del sector público que tienen menos de 40 años en el primer trimestre de 2018, un 59\% tiene un contrato o un nombramiento temporal, lejos del $44 \%$ de los hombres de la misma edad.

Igualmente frente a la idea de que el sector privado tiene menos estabilidad, en el $1^{\circ}$ trimestre de 2019 , entre las mujeres del sector privado de menos de 40 años, la temporalidad no sólo es mucho menor que en el sector público, un 35,6\% sino que es casi igual que la de los hombres, un $36,7 \%$.

La variabilidad de la temporalidad se explica por el ajuste de empleo público que se ha concentrado entre los que cuentan con un contrato temporal o un nombramiento indefinido, primero entre las mujeres, no importa la edad y luego entre los jóvenes, hombres y mujeres de menos de 40 años.

Por otra parte frente a la expectativa de inamovilidad, según la cual la administración cuenta con una especial protección frente al despido, llama la atención que el número de parados ${ }^{24}$ que anteriormente trabajaban como asalariados en el sector público haya pasado de 154.200 en $2002\left(1^{\circ} \mathrm{T}\right)$ a 309.200 en el momento de mayor desempleo proveniente del ámbito público, el $2^{\circ}$ trimestre de 2012, un incremento $^{25}$ muy importante del $96 \%$, que se ha visto reducido hasta 71.200 en el $2 \mathrm{~T}$ de 2018 .

24 Sobre el sector publico la EPA recoge datos de parados que han dejado su último empleo hace 12 meses o menos.

25 Estas proporciones son mucho más reducidas que las de los que trabajaban como asalariados en el sector privado que en las mismas fechas se incremento en un $125 \%$. 


\section{El empleo científico-técnico}

En el sector público la ocupación profesional más numerosa, un 44,2\% en 2018 , corresponde con el grupo de técnicos y profesionales, científicos e intelectuales, que incluye "las ocupaciones cuyas tareas principales requieren para su desempeño conocimientos profesionales de alto nivel y experiencia en materia de ciencias físicas y biológicas o ciencias sociales y humanidades. Sus tareas consisten en aplicar el acervo de conocimientos científicos o intelectuales a los diferentes campos o, por medio de la enseñanza asegurar la difusión sistemática de esos conocimientos"26, e incluye las ocupaciones que requieren contar con las titulaciones de los antiguos $1^{\circ}$, $2^{\circ}$ y $3^{\circ}$ ciclo universitario, y los actuales títulos de grado o postgrado.

Y el segundo grupo más numeroso, un 18,2\%, en 2018, es el de trabajadores de los servicios de restauración, personales, protección y vendedores, que entre otros integra a las fuerzas y cuerpos de seguridad locales, regionales o nacionales y se refiere a "las ocupaciones cuyas tareas principales requieren para su desempeño los conocimientos y la experiencia necesarios para la prestación de servicios ... relacionados con los trabajos domésticos, la restauración, los cuidados personales, la protección de personas y bienes, el mantenimiento del orden público o la venta de mercancías en un comercio o en los mercados"

En el conjunto de la economía el total del grupo científico técnico representa un $18,2 \%$ del total de los ocupados, proporción que, al no considerar a los parados, sitúa a España en la media Europea, por encima de Francia, Alemania e Italia, pero lejos de los países escandinavos, de los del BENELUX o del Reino Unido (en la Figura 6 los datos son del $1^{\circ}$ trimestre de 2018).

Figura 6. Proporción del grupo científico-técnico sobre ocupados

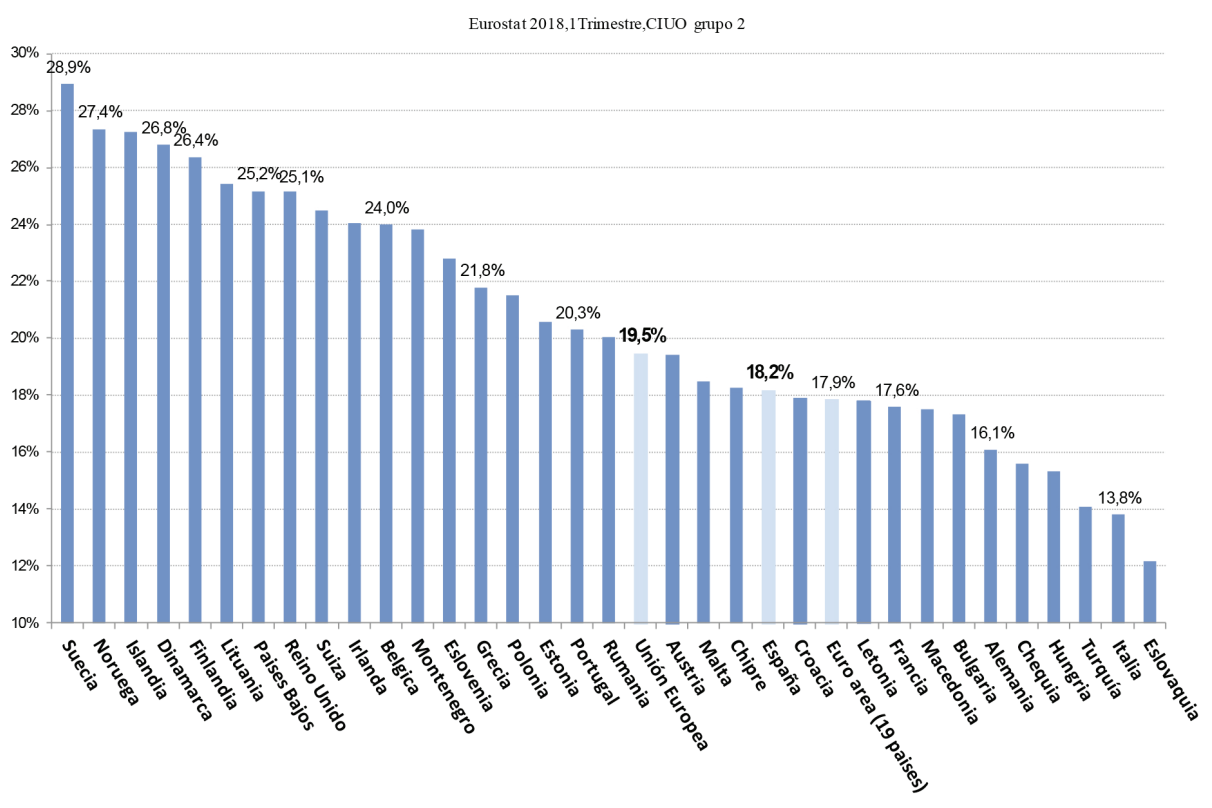

26 Clasificación Nacional de Ocupaciones Profesionales. INE. 
En la economía española, desde 2002 hasta 2018, el incremento del grupo de profesionales científico-técnicos ha sido muy importante, pasando de 2.014 .500 a 3.423.300. En total, un saldo neto que supone 1.408.800 ocupados adicionales. De ellos 383.400 se incorporaron al ámbito público; 796.300 al grupo de asalariados del sector privado, y entre los no asalariados fueron 229.100.

Entre 2002 y 2011 (Figura 7), aunque con distinta intensidad, el comportamiento del empleo público en el grupo científico-técnico es muy semejante al de los asalariados del sector privado $\left(\mathrm{R}^{2} 0,90\right)$. Mientras que desde 2012 hasta 2018 la correlación desaparece, y el comportamiento del empleo público en el grupo científico-técnico deja de tener la misma pauta $\left(\mathrm{R}^{2} 0,35\right)$ que los asalariados del sector privado.

Figura 7. Técnicos y profesionales, científicos e intelectuales

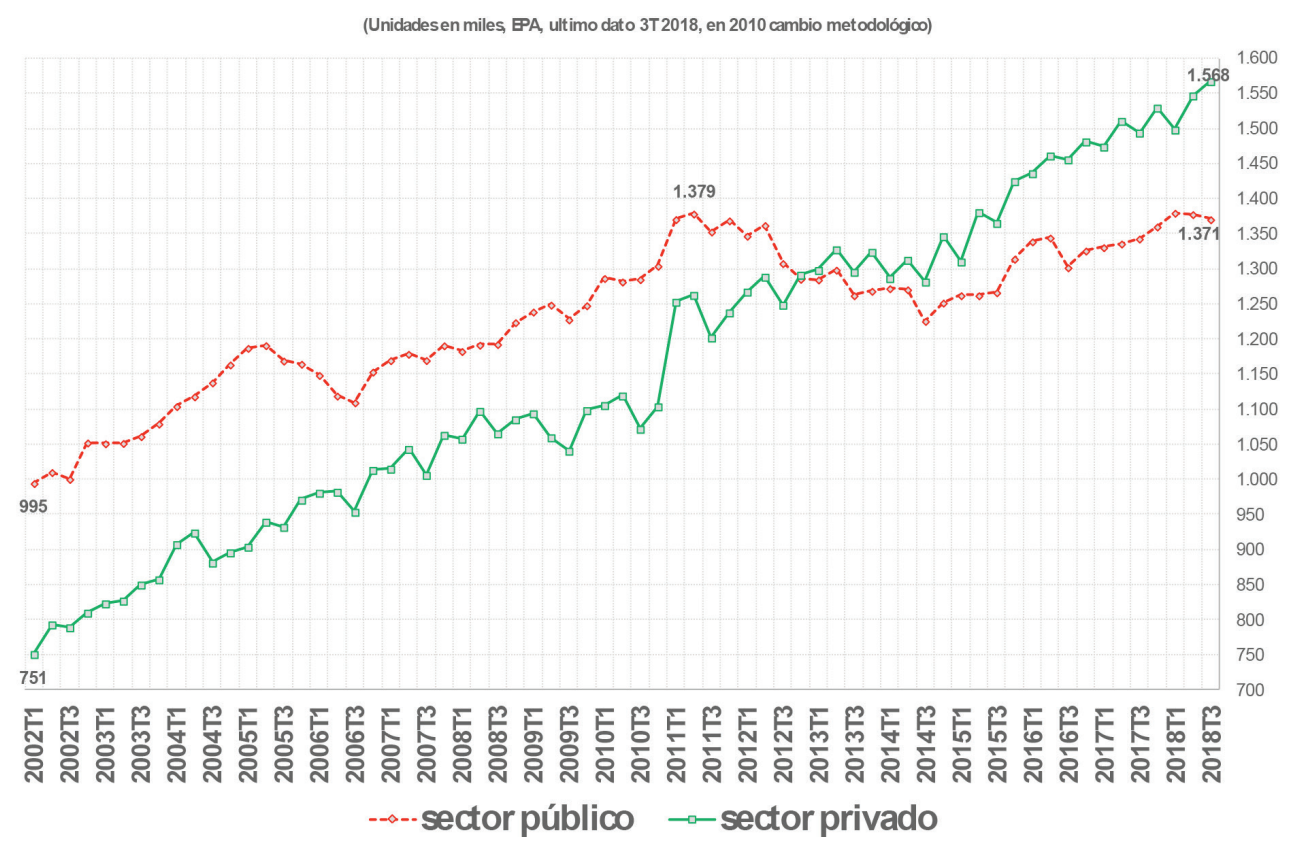

El peso del sector público en el grupo de profesionales científico-técnicos ha disminuido progresivamente pasando de un 57\% en el primer trimestre de 2002 a un $47,1 \%$ en el segundo trimestre de 2018 . Y por primera vez, a partir de 2013 , es más numeroso el grupo de profesionales científico-técnicos del sector privado.

Si se observa la Figura 7, desde el punto de vista de la variación del número de empleados públicos científico-técnicos, entre 2002 y 2018, pueden señalarse tres etapas:

a. Hasta 2004 (1 trimestre), el final de la segunda legislatura del presidente Aznar, el número de empleados públicos profesionales científico-técnicos creció una media de 13.710 empleos netos trimestrales.

b. En los años de gobierno del presidente Zapatero, hasta el tercer trimestre de 2006 hubo un ajuste del empleo público, que llego hasta una reducción de 
29.400 empleos científico-técnicos en el segundo trimestre de 2006. Mientras que desde 2006 (4 trimestre) hasta 2011 (4 trimestre), último trimestre del gobierno de Zapatero, el empleo público científico-técnico tiene de nuevo una fase expansiva, con una media de 12.350 empleos netos trimestrales.

c. Y por último en los años de gobierno del presidente Rajoy se pueden también distinguir dos periodos: Los primeros años, entre 2012 y 2014 (3 trimestre), se produce un nuevo ajuste del empleo público científico-técnico, más largo y más intenso, con una reducción media de 13.030 empleos netos trimestrales. Mientras que desde el cuarto trimestre de 2014 se inicia una nueva fase crecimiento, que incorpora algún trimestre de disminución, pero que en general supone un crecimiento medio de 10.500 empleos netos trimestrales.

\section{Discusión y conclusiones}

El sector público se caracteriza por su dependencia del poder político, su especialización en el interés general, por el empleo intensivo de técnicos y profesionales, científicos e intelectuales, y por la utilización masiva del contrato de lealtad, que para garantizar la imparcialidad y profesionalidad de los empleados públicos incorpora una exigencia de mérito y capacidad en la selección y promoción, y una garantía de inamovilidad reforzada.

Junto a este modelo, de modo excepcional, se acepta un ámbito de contratación o nombramiento temporal, para el que se abre un modo de selección más rápido, que se adapte a las necesidades coyunturales del servicio público o a los requerimientos de los sistemas de formación de profesionales, pero que no se adecua a las exigencias del ingreso en una carrera profesional, que se presume de larga duración.

La generalización de la contratación temporal, mayoritaria entre los menores de 40 años, especialmente entre las mujeres, indica un modelo dual de relaciones laborales, que supone una importante disfunción de la naturaleza del empleo público.

Un contrato temporal, ajeno a la conducta de lealtad, típica de las organizaciones públicas, seria aquel en el que el trabajador no cuenta con la suficiente pericia, conocimiento del contexto e imparcialidad, para contrabalancear las instrucciones imprecisas susceptibles de ser alteradas en cualquier momento, que recibe desde el poder político.

Pareciera que en el conjunto del sistema público se han extendido las pautas de selección que caracterizan a la ciencia, a la educación o a la sanidad, que suman la mitad del empleo público, que requieren una titulación de postgrado, máster, doctorado o título de especialista, y que para participar en una oferta laboral con permanencia, añaden uno o dos postdoc, o sucesivas suplencias y contratos de interinidad, en un proceso que puede concluir en un reconocimiento formal de acreditación o contar con una exigencia de experiencia temporal previa, y que a modo de periodo de prueba, puede alargarse durante años.

La volatilidad del empleo científico-técnico y el uso de la contratación temporal, como instrumento habitual en el ajuste o en la expansión de las políticas públicas, se abrió paso asociado al marco teórico de la nueva gestión pública, que atrae una lógica de racionalidad mercantil, enfrentada a la racionalidad política del Estado.

Un cuadro en el que la orientación del empleo público se impulsa a partir de criterios de política económica, orientados a favorecer el crecimiento de la economía, y 
reducir el déficit público, objetivos que por su propia naturaleza se adoptan desde el ámbito de la racionalidad política y no de la racionalidad mercantil, pero que han operado sin una consideración expresa sobre sus efectos en la calidad de las políticas públicas a las que atiende, y cuyas decisiones más relevantes sobre el empleo público, implican de manera rígida a la totalidad de las instituciones públicas, y se adoptan por el Gobierno, de manera detallada y centralizada, en el debate de los Presupuestos Generales del Estado, modulado, en su caso, por el peso de los acuerdos Gobierno-Sindicatos y por la influencia de las administraciones territoriales y funcionales.

La expansión de la temporalidad, más allá de las necesidades coyunturales o de los requerimientos de la formación, implica una tendencia de ruptura del contrato de lealtad, hasta ahora asociado a la inamovilidad del empleo público, y supone una orientación de racionalización de mercado de las relaciones laborales públicas que modifica los sistemas de mérito, que le diferenciaban tanto de los modelos de spoils system, como de las pautas laborales del sector privado que, con mayor o menor coste, admiten el despido.

Frente a la idea de que son más numerosos los contratados indefinidos en el ámbito público que en el sector privado y que su variación esta menos asociada al ciclo económico y que no está sustancialmente vinculada al ciclo político, sino al desarrollo de las políticas públicas, puede objetarse que en los últimos años la temporalidad no sólo es muy alta, mayor que entre los empleados del sector privado, sino que además la temporalidad es mayoritaria entre los empleados públicos que pertenecen a las generaciones nacidas en la democracia.

En los últimos años en el ámbito público se ha acentuado una pauta de relaciones laborales dual, en la que a las mujeres y a los jóvenes se oferta precariedad, que implica inseguridad, retribuciones menores y contratación flexible, y se reserva la estabilidad del contrato de lealtad, las retribuciones mayores y la carrera profesional para los mayores.

De manera general, a diferencia del sector privado, en el ámbito público se ha frenado el ritmo de incorporación masculina de profesionales y técnicos, científicos e intelectuales. Las causas de este comportamiento podrían buscarse en el lado de la demanda en que previamente la tasa de actividad masculina es mayor y en el diferencial de caudal de formación acumulado por hombres y mujeres; y del lado de la oferta en la especialización del sector público en los ámbito sanitario y educativo, y en la orientación de la política de empleo público.

Esta línea de quiebra del contrato de lealtad opera en un marco en el que España cuenta con una administración pública relativamente pequeña, tiene menos empleados y dedica al sector público menos recursos que el promedio de países de la OCDE y de la Unión Europea, pero que sin embargo, aunque sus costes de producción son menores, para retribuir a sus empleados públicos, en términos de PIB, gasta algo más que el promedio OCDE.

Una administración, mucho más envejecida que la población, en la que el grupo mayoritario de sus empleados forman parte de las generaciones predigitales, cuya primera formación fue previa al cambio político y al proceso de modernización socioeconómica de la democracia. Una organización con un reducido peso de las generaciones digitales, cuya socialización convive con la madurez del régimen constitucional, con la globalización y la expansión de las nuevas tecnología, pero cuya incorporación a la vida laboral se desarrolla en el marco del impacto de la crisis económica 2008-2013. 
La administración al incrementar la dualidad de las relaciones laborales y disminuir el ritmo de incorporación de profesionales científico-técnicos, y al tiempo reducir la presencia de las cohortes de edad formadas en la democracia, puede haber frenado su capacidad de comprensión, innovación y liderazgo de la sociedad del conocimiento, lo que a medio plazo dificulta sus posibilidades de adaptación y pone en cuestión su capacidad de liderar un proceso de cambio social al que está obligada para remover los obstáculos que impidan o dificulten la igualdad.

\section{Bibliografía}

Agencia Tributaria. (2016). Mercado de trabajo y pensiones en las fuentes tributarias. Recuperado en: http://www.agenciatributaria.es (Consultado, el 1 de diciembre de 2017).

Arenilla Sáez, M., \& Delgado Ramos, D. (2014). “HHay muchos empleados públicos en España?" en Revista de Administración Pública, 193: 297-334.

Areses, X., Blanco, C., Colmenares, P., Gallego, A., Gómez, G., Íñiguez, S., Fernández, E. (2017). Nuevos tiempos para la función pública. Propuestas para atraer y desarrollar el talento en la Administración general del Estado. Madrid: Instituto Nacional de Administración Pública.

Comisión para el estudio y preparación del Estatuto Básico del Empleado Público. (2005). Estatuto Básico del Empleado Público. Informe de la Comisión. Madrid: Instituto Nacional de Administración Pública.

Consejo Económico y Social. (2017). La participación laboral de las mujeres en España. Madrid: Consejo Económico y Social.

Domínguez Martín, R., \& Sánchez-Sánchez, N. (2007). "Los diferenciales salariales por género en España durante el desarrollismo franquista", en Revista de Investigaciones Sociológicas, 117:143-160.

Du Gay, P. (2012). En elogio de la burocracia.Weber: Organización, Ética.Madrid: Siglo XXI.

Faria Lopes, I. M. (2012). Isabel Maria Paraíso Faria Lopes. Política de austeridad y contrato psicológico en la administración pública. Badajoz: Universidad de Extremadura.

Instituto nacional de Estadística. (2014). Estadística de flujos de la población activa. Metodología para el cálculo del flujo en valores absolutos. Madrid: INE.

Instituto Nacional de EStadística. (2016). El empleo de las personas con discapacidad. Explotación de la Encuesta de Población Activa y de la Base Estatal de Personas con discapacidad. Metodología y descrpción de la operación. Madrid: INE.

Instituto Nacional de Estadistica. (2017). Cuentas trimestrales no financieras de los sectores institucionales. Metodología. Recuperado en: http://www.ine.es (Consultado, el 1 de diciembre de 2017).

Instituto Nacional de Estadística. (2017). Encuesta de Población Activa. Metodología 2005, Descripción general de la Encuesta. Madrid: Instituto Nacional de Estadística. Madrid: INE. Instituto Nacional de Estadística. (Noviembre de 2013). Instituto Nacional de Estadística. El Salario del Empleo Principal en la Encuesta de Población Activa Explotación estadística de los Registros de la Seguridad Social y de las Agencias Tributarias. Madrid: INE.

Instituto Nacional de Estadística. Area de Diseño de Muestras y Evaluación de Resultados. (2016). Encuesta de Población Activa. Diseño de la Encuesta y Evaluación de la calidad de los datos. Informe Técnico. Madrid: INE. 
Instituto Nacional de Estadítica. (2014). El empelo de las personas con discapacidad. Explotación de la Encuesta de Población Activa y de la Bases Estatal de Personas con Discapacidad. Metodología y descripción general de la operación. Madrid: INE.

Intervención General del Estado. (2016). Personal al servicio del sector público estatal 2016. Madrid: IGAE.

Jordana, J., \& Ramió, C. (2005 (2a)). Gobierno y Administración. En A. Carreras, \& X. Tafunell (Edits.), Estadisticas históricas de España: siglos XIX-XX. Bilbao: Fundación BBVA.

Lindert, P. (2011). El ascenso del sector público. El crecimiento económico y el gasto social del siglo XVIII al presente. México: Fondo de Cultura Económica.

Luxán Meléndez, J. M. (2016). "El impacto de la crisis en las retribuciones del sector público", en Cuadernos de Gobierno y Administración Pública, 3 (2): 143-169.

Luxán Meléndez, J. M. (2018). "Brecha salarial o discriminación laboral. Retribuciones y carrera profesional de las mujeres en el sector público", en Derecho de la Relaciones Laborales, 3: 287-304.

Luxán Meléndez, J. M. (2018).’Las políticas de emlpeo público en España (1996-2017): diagnóstico y propuestas para su modernización y eficiencia", en Revista del Ministerio de Trabajo.

Luxán Meléndez, J. M. (2019). “Las políticas de empleo público en España (1996-2017): diagnóstico y propuestas para su modernización y eficiencia", en Revista del Ministerio de Empleo y Seguridad Social-Economía y Sociología-, aceptado el 6 de marzo de 2018.

Luxán Meléndez, J. M. (2019). "Las políticas de empleo público en España (1996-2017): diagnóstico y propuestas para su modernización y eficiencia", en Revista del Ministerio de Empleo y Seguridad Social-Economía y Sociología-, aceptado el 6 de marzo de 2018.

Luxán Meléndez, J. M. (2019). "Las políticas de empleo público en españa (1996-2017): Diagnóstico y propuestas para su modernización y eficiencia”, en Revista del Ministerio de Trabajo (aceptado el 6/03/2018).

Magno, J. M., \& Vivente Castro, F. (2017). "Contrato psicológico: Formalização da linguagem”, en International Journal of Developmental and Educational Psychology, 3: 367376.

Martínez, M., \& Pérez, J. (2017). La evolución del empleo de las adminidtraciones públicas en la última década. Madrid: Banco de España.

Monereo Pérez, J. L. (Ed.). (2015). La concertación social en España: Una evaluación de su trayectoria en la perspectiva de los cambios socieconómicos. Madrid: Consejo Económico y Social.

Montesinos, A., Perez, J., \& Ramos, R. (2014). El empleo de las administraciones públicas en españa caracterización y evolución durante la crísis. Madrid: Banco de España.

OCDE. (2016). Panorama de las administraciones públicas 2015. Madrid 2016: Instituto nacional de la Administración Pública.

OCDE. (2017). Government at a glance. Paris: OCDE.

OCDE. (2017). Panorama des administrations publiques 2017. Paris: OCDE.

Olías de Lima, B. (1995). Gestión de recursos humanos en las administraciones públicas. Madrid: Editorial Complutense.

Olías de Lima, B. (2006). Manual de organización administrativa del Estado. Madrid: Síntesis.

Olmeda, J. A., Parrado, S., \& Colino, C. (2017). Las administraciones públicas en España (2 edición ed.). Valencia: Tirant lo Blanch.

Organización Internacional del Trabajo. (2007). Resolución sobre la actualización de la clasificación internacional uniforme de ocupaciones. Ginebra: OIT. 
Organización Internacional del Trabajo. (2015). Estrategia y plan de acción para la inclusión de la discapacidad 2014-2017. Ginebra:OIT.

Organización Internacional del Trabajo. (2016). Las mujeres en el trabajo, tendencias 2016. Ginebra: OIT.

Osborne, D., \& Gaebler, T. (1995). La reinvención del gobierno. La influencia del espiritu empresarial en el sector público ( $\left.1^{a} 1992\right)$. Barcelona: Paidos.

Paraiso, I. (2012). Isabel Maria Paraíso Faria Lopes Política de austeridad y contrato psicológico en la administración pública. Badajoz: Universidad de Extremadura.

Paraiso, I., \& Vicente Castro, F. (2014). "Política de austeridade e contrato psicológico na administração pública", en Revista de Análisis Transacional y Psicología Humanista, 343632.

Parrado, S. (2017). "Los empleados de la Administración General del Estado", en J. A. Olmeda, S. Parrado, \& C. Colino (ed.). Las administraciones públicas en España. Valencia: Tirant lo Blanch.

Registro Central de Personal. (2017). Boletín estadístico del personal al servicio de las Administraciones Públicas. Registro Central de Personal. Madrid: Ministerio de Hacienda y Función Pública.

Sánchez-Mira, N. (2017). “La brecha salarial y las desigualdades de género en el mercado de trabajo. Una revisión de aproximaciones teóricas y aproximaciones empíricas", en Anuario IET de trabajo y Relaciones laborales, 87-97.

Scanlon, G. M. (2007). "Orígenes y evolución del movimiento feminista contemporaneo", en P. Folguera (Ed.), El feminismo en España. Dos siglos de Historia. Madrid: Editorial Pablo Iglesias.

Stiglitz, J. E. (1993). El papel económico del Estado. Madrid: Instituto de Estudios Fiscales.

Stiglitz, J. E., \& Rosengard, J. K. (2015). La economía del sector público. Barcelona: Antoni Bosch.

Subirats, J., Knoepfel, P., Larrue, C., \& Varone, F. (2012). Análisis y gestión de políticas públicas. Barcelona: Ariel.

Vallès, J. M., \& Martí i Puig, S. (2015). Ciencia política. Un manual. Barcelona: Ariel.

Vega Catena, P. J. (2014). La diferencia salarial por sexo en España. Un análisis a partir de la encuesta de estructura salarial.2006. Madrid: Tesis Doctoral en Universidad Rey Juan Carlos. 
